\title{
POSSIBILITIES OF IMPLEMENTING TRADITIONAL POLISH GAMES AND PLAY IN THE PROCESS OF PHYSICAL EDUCATION ACCORDING TO PE TEACHERS
}

\author{
IGOR CIEŚLIŃSKI', IRENEUSZ CHALIBURDA²
}

\author{
Józef Piłsudski University of Physical Education in Warsaw, Faculty of Physical Education and Sport in Biała \\ Podlaska, Department of Theory and Methodology of Physical Education ${ }^{1}$, Department of Anthropology and \\ Anthropomotorics ${ }^{2}$
}
Mailing address: Igor Cieśliński, Faculty of Physical Education and Sport in Biała Podlaska, Department of Theory and Methodology of Physical Education, 2 Akademicka Street, 21-500 Biała Podlaska, tel.: +48 83 3428742, fax: +48 83 3428800, e-mail: igorcieslinski@gmail.com

\begin{abstract}
Introduction. Physical education programmes are primarily based upon sports that originated in the Western European tradition. Implementing indigenous traditions such as traditional Polish games and play is an excellent opportunity to make those programmes more modern and attractive. In order to make use of the value and potential of these activities, it is necessary to introduce them into the programmes of Polish schools. This study sought to show the chances of traditional Polish forms of activity becoming a permanent part of physical education lessons and make present and future PE teachers aware of the fact that such forms of activity exist. Material and methods. The study included 125 PE teachers (62 females and 63 males) from randomly selected schools in eastern Poland. It was carried out with the use of a diagnostic survey, which included an original questionnaire designed by the author consisting of questions regarding the subjects' knowledge of traditional Polish games and play, their place and role in national culture, as well as the possibility of using them in physical education. Correspondence analysis was employed to examine the data. Results. The research revealed that the participants of the study were relatively poorly prepared to be promoters and continuers of traditional Polish games, play, and sports. This mainly stemmed from the fact that they were hardly aware of the role of those forms of activities in the process of physical education and had little knowledge of traditional forms of physical activity that originate in indigenous culture. Conclusions. The teachers examined are insufficiently prepared to introduce traditional Polish games, play, and sports into the process of physical education. It is necessary to broaden the programme and educational offerings in the field of national heritage regarding traditional forms of physical activity that come from national cultures.
\end{abstract}

Key words: ethnology of sports, cultural anthropology, traditional Polish games and play

\section{Introduction}

Despite criticism, nearly all forms of physical activity implemented in physical education programmes in Poland are still based upon a few very popular Olympic sports that originate in the Western European tradition. The postulate of programme diversity and attractiveness is insufficiently realised, because modernity means not only following trends and fashions promoted by mass media but also fostering tradition. Taking indigenous traditions such as traditional Polish games and play into consideration is an excellent opportunity for teachers to realise the postulate of diversity and attractiveness more broadly. Traditional games, sports, and play have been an area of interest for foreign scientists for a long time. The early 1990s even saw a big comeback here [1]. As far as Polish scientists are concerned, in the last fifteen years they have become more interested in those forms primarily owing to the works of Lipoński [2] and Bronikowska [3]. However, their studies mostly refer to games and play from western Poland. In addition, in Poland there are general works that indicate the relevance of conducting research in the field of traditional sports and games $[4,5]$. Nevertheless, so far such studies have mainly focused on the theoretical and historical foundations of the issue as well as searching for and describing still-living traditions and presenting them during various types of festivals of traditional games and play.

In order to take full advantage of the value and potential of traditional games and play, it is necessary to introduce them into the programmes of Polish schools. Here a few questions arise regarding, for example, the chances of a permanent presence of traditional Polish forms of activity in physical education lessons and the extent to which present and future PE teachers are aware of the fact that such forms exist and possess the methodological knowledge necessary to use traditional Polish games and play during lessons in an unchanged form or in a form adjusted to modern times. This work seeks to answer some of the abovementioned questions. It is also part of a broader project aimed at establishing procedures that would facilitate the practical implementation of traditional sports and games in the process of physical education. One aim of this project is to define present teachers' knowledge and, consequently, their preparation for implementing such activities in class. This task was completed in the present study. Further studies will focus on conducting similar analyses involving future teachers (current students of physical education) as well as putting forward practical methodological solutions. 
The aim of this work is to determine whether Polish PE teachers possess sufficient knowledge to implement traditional Polish games and play and to find out whether they can see their value in terms of curricular and extracurricular physical education.

\section{Material and methods}

The study included 125 PE teachers (62 females and 63 males) from randomly selected schools in eastern Poland. The group consisted of 3 junior teachers, 10 contract teachers, 24 appointed teachers, and 88 certified teachers. Their mean teaching experience was 14.2 years for women and 16.1 years for men.

The study was carried out with the use of a diagnostic survey, which included a questionnaire designed by the author consisting of questions regarding the participants' knowledge of traditional Polish games and play, their place and role in national culture, as well as the possibilities of using them in physical education. However, the most important part of the questionnaire was a list of games and play activities collected from written sources and obtained by the authors in a previous research project that focused on games and play originating in eastern Poland. When going through the list, the teachers stated that they knew the rules of a game or play activity in detail or that they knew its name (or a regional variation of its name) only.

The data were analysed by means of the R program using the ca [6] and vcd [7] packages. Apart from descriptive statistics and analyses of contingency tables, correspondence analysis (both quantitative and graphic - perceptual mapping) was employed in the study. Such variables as teaching experience in years and the number of games known to the research participants were categorised using quartiles. Due to publishing limitations, only statistically significant correlations are presented in the results.

\section{Results}

The first issue analysed was the level of knowledge regarding traditional games and play. The participants of the study could state that they were aware of a given game together and its detailed rules or that they knew the name of the game without knowing its rules.

Table 1. Basic quantity indices regarding the knowledge of traditional Polish games and play $(\max =124)$

\begin{tabular}{|c|c|c|c|c|c|c|c|c|}
\hline Sex & \multicolumn{4}{|c|}{ Women } & \multicolumn{5}{c|}{ Men } \\
\cline { 2 - 8 } Response & $\min$ & median & $\max$ & mean & $\min$ & median & $\max$ & mean \\
\hline $\begin{array}{c}\text { I know it and } \\
\text { I know the } \\
\text { rules }\end{array}$ & 0 & 7 & 33 & 7.83 & 0 & 6 & 18 & 6.33 \\
\hline $\begin{array}{c}\text { I know it } \\
\text { but I don't } \\
\text { remember } \\
\text { the rules }\end{array}$ & 0 & 1 & 109 & 7.5 & 0 & 4 & 118 & 6.48 \\
\hline
\end{tabular}

The level of knowledge regarding traditional games and play turned out to be relatively low, particularly in terms of their rules. However, a few female teachers knew several dozen games. Still, the vast majority of respondents could only identify fewer than ten games. Also, there were quite a few individuals who did not know any of the games (tab. 1).

The participants were also asked if traditional regional culture could be a significant source of inspiration when looking for less well-known forms of activity that would be useful in physical education. Most of the respondents claimed that the role of regional culture in seeking and implementing less known traditional forms of activity was marginal. Slightly more men saw regional culture as valuable for seeking and implementing less well-known forms of activity. However, the differences in the responses of the women and men turned out to be insignificant, i.e. the responses did not depend on the gender of the respondents (fig. 1).

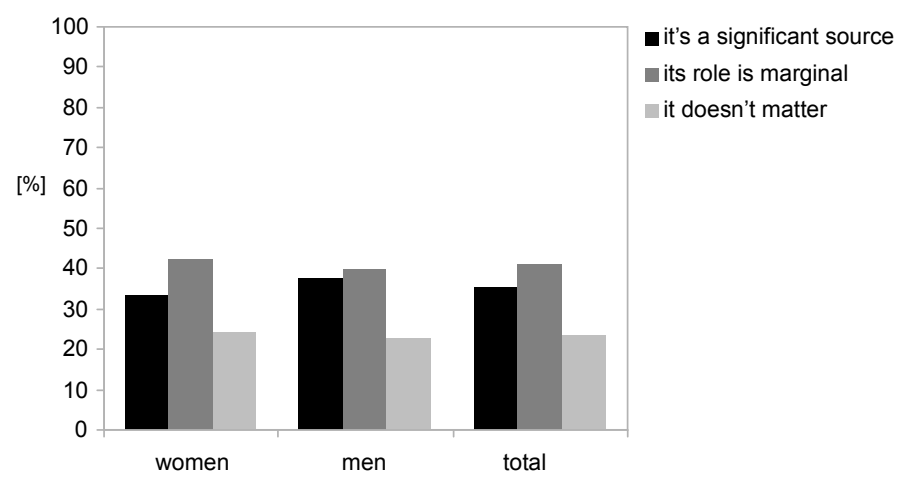

Figure 1. Respondents' gender and opinion regarding regional culture as a source of inspiration for seeking and implementing traditional games and play

Further detailed analyses revealed that the respondents' opinions concerning the role of regional culture as a source of inspiration for seeking and implementing traditional forms of activity did not correlate significantly with the university the respondents had graduated from, their place of residence, or their having practised sports. However, different results were obtained in regard to the teaching experience of the PE teachers: here the correlation was significant at the level of $\mathrm{p}<0.05$. It was also noticeable that the value of regional culture was mainly recognised by teachers with average professional experience (fig. 2).

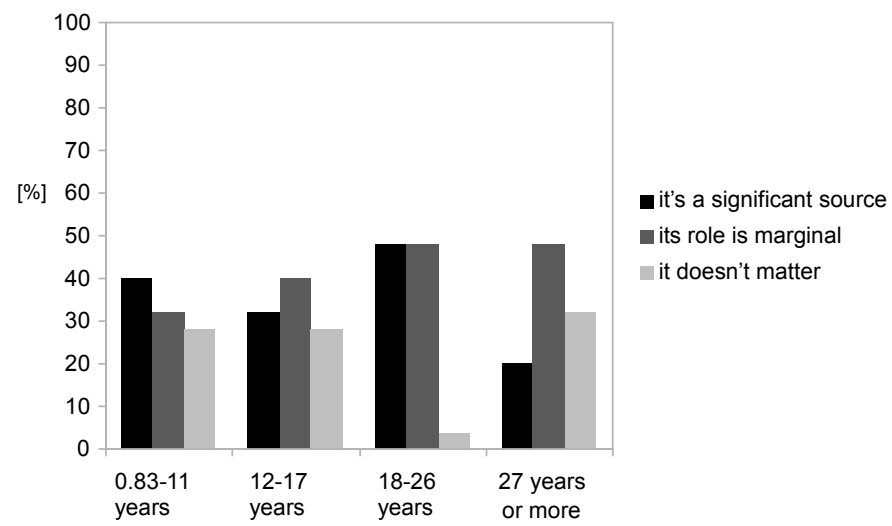

Figure 2. Respondents' teaching experience and opinion regarding regional culture as a source of inspiration for seeking and implementing traditional games and play 
The correspondence analysis performed afterwards showed that the correlation between teaching experience of the respondents and their assessment of the value of regional culture was not high, because the value of total inertia was 0.09, with the first dimension accounting for $82.5 \%$ of that inertia. The "it doesn't matter" category formed the biggest part of the first dimension, as it accounted for $68.5 \%$ of that dimension. In turn, the "its role is marginal" category was the main element of the second dimension (56.8\%). When it comes to teaching experience, though, it turned out that the first dimension was mainly formed by the experience category of "18-26 years" $(67.3 \%)$, whereas the second (less important) dimension was dominated by the category of "0.83-17 years" (56.7\%). On the basis of squared correlation, the first dimension accounted for $97.4 \%$ of the inertia for the "it doesn't matter" category and for $81.2 \%$ for the "it's a significant source" category. The second dimension accounted for $92.2 \%$ of the inertia for the "its role is marginal" category. In turn, the categories of "18-26 years" and "over 26 years" were very well accounted for by the first dimension (95.8\% and $98.2 \%$, respectively), while the " $0.83-17$ years" category was dominated by the second dimension $(89.8 \%)$. This would mean that individuals with average teaching experience are more likely to recognise the value of regional culture as a source of inspiration for seeking and implementing traditional games and play (tab. 2, fig. 3).

Table 2. Results of correspondence analysis for such variables as the respondents' teaching experience and opinion regarding the role of regional culture in seeking and implementing traditional games and play*

\begin{tabular}{|c|c|c|c|c|c|c|c|}
\hline \multicolumn{7}{|c|}{ Rows } \\
\hline Category & Mass & Quality & Inertia & $\begin{array}{c}\text { Dimension } \\
1 \text { squared } \\
\text { correlation }\end{array}$ & $\begin{array}{c}\text { Dimension } \\
1 \text { absolute } \\
\text { contribution }\end{array}$ & $\begin{array}{c}\text { Dimension } \\
\text { 2 squared } \\
\text { correlation }\end{array}$ & $\begin{array}{c}\text { Dimension } \\
2 \text { absolute } \\
\text { contribution }\end{array}$ \\
\hline $\begin{array}{c}\text { It's a } \\
\text { significant } \\
\text { source }\end{array}$ & 353 & 1000 & 311 & 812 & 305 & 188 & 342 \\
\hline $\begin{array}{c}\text { Its role is } \\
\text { marginal }\end{array}$ & 422 & 1000 & 106 & 78 & 10 & 922 & 568 \\
\hline $\begin{array}{c}\text { It doesn't } \\
\text { matter }\end{array}$ & 225 & 1000 & 583 & 974 & 685 & 26 & 90 \\
\hline & 245 & 1000 & 108 & 102 & 13 & 898 & 567 \\
\hline $0.83-11$ & 245 & 1000 & 43 & 958 & 50 & 42 & 10 \\
\hline $12-17$ & 245 & 1000 & 657 & 982 & 673 & 18 & 59 \\
\hline $18-26$ & 265 & 1000 & 281 & 779 & 265 & 221 & 363 \\
\hline Over 26 & 245 & 100 & & & \\
\hline
\end{tabular}

* - the values in the table were multiplied by 1000 for clarity $(1=100 \%)$.

Another significant correlation (at the level of $\mathrm{p}<0.01$ ) was that between the respondents' knowledge regarding traditional games and play and the statement that regional culture is a significant source of traditional games. In this case the only significant correlation concerned the respondents' declaration of the importance of regional culture and their full knowledge of a given game or play activities (fig. 4). Here we need to highlight the fact that a large part of games and play that the participants marked as known originated in cultures of national and ethnic minorities that lived and still live in the area where the study was conducted. However, because of publishing limitations, a detailed analysis of this issue will be presented in another publication.

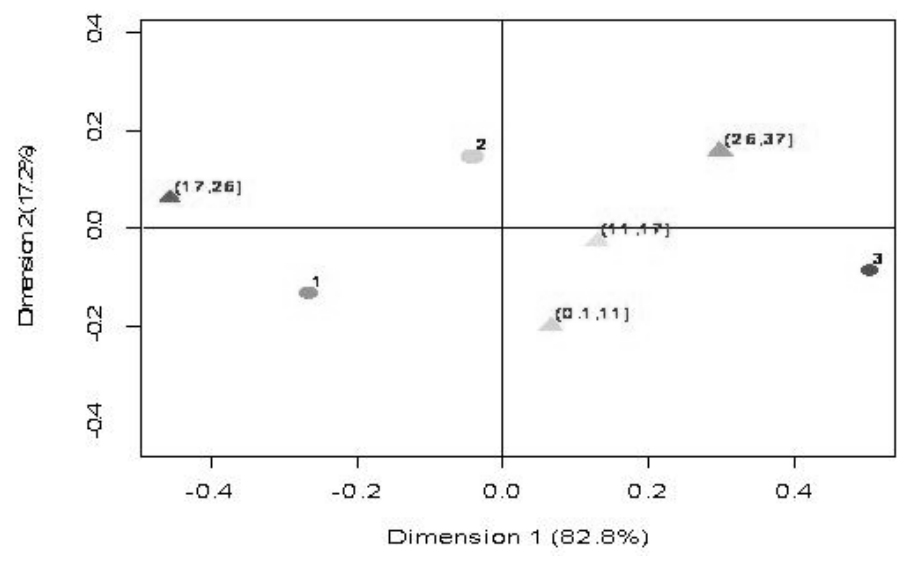

Symbols: 1 - "it's a significant source", 2 - "its role is marginal", 3 - "it doesn't matter"; $0.1,11$ - teaching experience from 1 month to 11 years; 12,17 - teaching experience from 12 to 17 years; 18,26 - teaching experience from 18 to 26 years; 27,37 - teaching experience of 27 years and more.

Figure 3. Perceptual map - correlations between the respondents' teaching experience and their opinion regarding regional culture as a source of inspiration for seeking and implementing traditional games and play

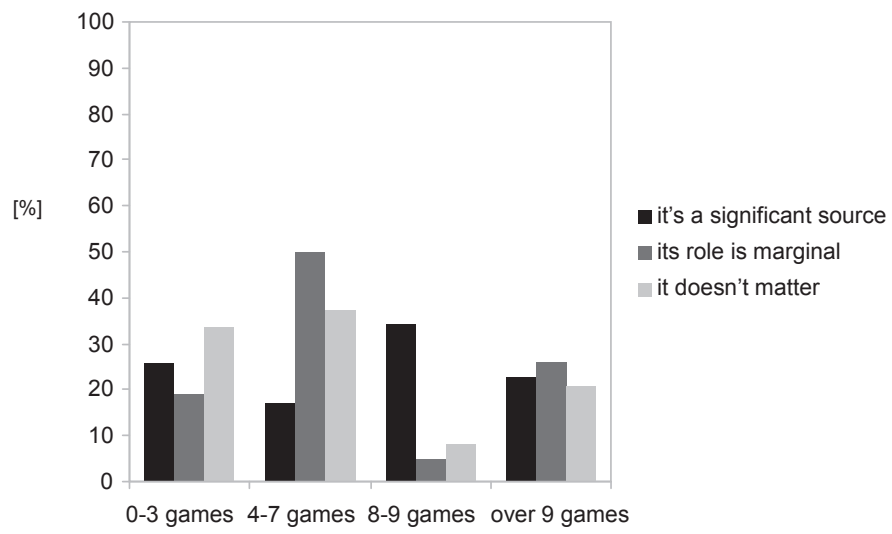

Figure 4. Respondents' knowledge regarding traditional games and play and their opinion regarding regional culture as a source of inspiration for seeking and implementing traditional games and play

In the correspondence analysis, total inertia was 0.19 , which points to a moderate correlation. Here the first dimension accounted for $90.5 \%$ of total inertia. The largest part of that dimension was formed by the "it's a significant source" category $(62.4 \%)$, while in the second dimension, it was the "it doesn't matter" category (73.9\%). In the case of the variable "the number of known games", the most important category was "8-9 games" for the first dimension (65.8\%) and "0-3 games" for the second dimension (70.3\%). On the basis of squared correlation, the first dimension accounted for $99.6 \%$ of inertia for the "it's a significant source" category and for $93.3 \%$ for the "its role is marginal" category, while the second dimension accounted for $69.4 \%$ of inertia for the "it doesn't matter" category. As far as the number of games known is concerned, two categories prevailed, i.e. "4-7 games" and "8-9 games", accounted for by the first dimension (99.5\% and $99.3 \%$, respectively). The " $0-3$ games" category was well accounted for by the second dimension (70.3\%). The interpretation of the data and perceptual map indicates 
that the participants who knew between 4 and 7 games mainly saw the role of regional culture as marginal, while those who knew from 8 to 9 games chose "it's a significant source". Considering the fact that in terms of inertia this is the most important category, these results indicate a strong correlation between the knowledge of games and the recognition of regional culture as a significant source of knowledge and inspiration concerning the use of traditional games and play (tab. 3, fig. 5).

Table 3. Results of correspondence analysis for such variables as the number of games and play activities known to the respondents and their opinion regarding the role of regional culture in seeking and implementing traditional games and play*

\begin{tabular}{|c|c|c|c|c|c|c|c|}
\hline \multicolumn{7}{|c|}{ Rows } \\
\hline Category & Mass & Quality & Inertia & $\begin{array}{c}\text { Dimension } \\
1 \text { squared } \\
\text { correlation }\end{array}$ & $\begin{array}{c}\text { Dimension } \\
1 \text { absolute } \\
\text { contribution }\end{array}$ & $\begin{array}{c}\text { Dimension } \\
\text { 2 squared } \\
\text { correlation }\end{array}$ & $\begin{array}{c}\text { Dimension } \\
\text { 2 absolute } \\
\text { contribution }\end{array}$ \\
\hline $\begin{array}{c}\text { It's a } \\
\text { significant } \\
\text { source }\end{array}$ & 351 & 1000 & 568 & 996 & 624 & 4 & 25 \\
\hline $\begin{array}{c}\text { Its role is } \\
\text { marginal }\end{array}$ & 423 & 1000 & 332 & 933 & 342 & 67 & 236 \\
\hline $\begin{array}{c}\text { It doesn't } \\
\text { matter }\end{array}$ & 227 & 1000 & 101 & 306 & 34 & 694 & 739 \\
\hline $\begin{array}{c}0-3 \\
\text { games }\end{array}$ & 227 & 1000 & 73 & 92 & 7 & 908 & 703 \\
\hline $\begin{array}{c}4-7 \\
\text { games }\end{array}$ & 371 & 1000 & 303 & 995 & 333 & 5 & 17 \\
\hline $\begin{array}{c}8-9 \\
\text { games }\end{array}$ & 165 & 1000 & 599 & 993 & 658 & 7 & 42 \\
\hline $\begin{array}{c}10-33 \\
\text { games }\end{array}$ & 237 & 1000 & 24 & 56 & 1 & 944 & 238 \\
\hline
\end{tabular}

* - the values in the table were multiplied by 1000 for clarity $(1=100 \%)$.

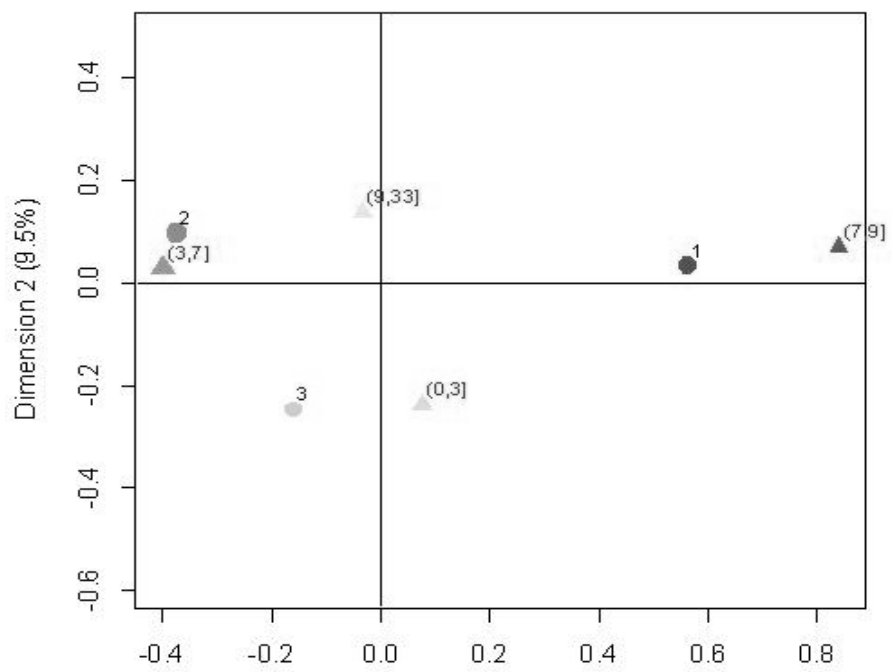

Symbols: 1 - "it's a significant source", 2 - "its role is marginal", 3 - "it doesn't matter"; 0,3 - the knowledge of 0 to 3 games, 4,7 - the knowledge of 4 to 7 games, 8,9 - the knowledge of 8 to 9 games, 9,33 - the knowledge of over 10 games.

Figure 5. Perceptual map - correlations between the respondents' opinion regarding regional culture as a source of inspiration for seeking and implementing traditional games and play and the number of games and play activities known to them

\section{Discussion}

In general, those interested in the issue of traditional games, play, and sports agree that they are a particularly valuable subject of research that can be and often is of different scope and character. They can be analysed from an anthropological viewpoint as an intercultural phenomenon, which makes it possible to explain many of the phenomena observed in the life of a contemporary human being in terms of nature and culture [8]. Traditional games have also been a subject of research which has aimed at discovering social models with their help [9]. Furthermore, there are some play activities and games which reflect a socio-cultural order. Sutton-Smith [10] claims that they are often a significant element of identity which ethnic groups include in projects connected with creating socio-cultural bonds. Extensive research has also been carried out on two large groups living in selected territories. For instance, Renson and van Mele [11] published extensive findings concerning games and play activities in South America. Their research as well as other studies provide substantial evidence of the considerable value of traditional games and play. However, the majority of those projects focus on preserving heritage in museum settings. Renson [1], who approached traditional games and play from the point of view of a museologist, wondered how to preserve non-Olympic games and play and what challenges they posed for museology. Piasecki was driven by similar motives, as he considered games and play to be an element of national heritage. He collected ample data that allowed him to preserve and describe more than one hundred traditional games [12].

The initiatives mentioned above, valuable as they might be, are insufficiently focused on educational practice. The promotion of traditional games and play ought to include not only initiatives taken by groups of enthusiasts or even European Union programmes such as "Recall: Games of the Past - Sports for Today" or UNESCO programmes. Owing to their overall value, traditional games should be widely introduced into the mainstream of physical education at schools. This would require educating teachers who would be capable of implementing them in the process of physical education, which, in turn, would mean introducing content directly connected with this element of national heritage into teacher training programmes. Obviously, limiting oneself to one's own heritage can only produce partial results, since traditional games and sports are part of the cultural heritage of all humanity. Abrignani [13] explained this in an excellent manner by stating that traditional sports and games are part of our intangible heritage and a symbol of cultural differences. They are also an effective way of passing on universal values, openness, and cultural awareness. Moreover, they may form ties between cultures for better mutual understanding. This is essential, especially at a time when some values may disappear as a consequence of globalisation and industrialisation. The possibility of loss is partly borne out by this study, as the oldest teachers demonstrated little knowledge of traditional games and play, which may stem from some stigmatisation and conscious rejection of traditional culture. This phenomenon was common in eastern regions in times of political and industrial changes, which is confirmed by the study of Czykwin [14].

All the aforementioned advantages do not make up a complete list of potential benefits that would result from spreading knowledge regarding traditional games and play and from their practical implementation. There are also works that point to other profits of their practical application. A study conducted in Iran proved that 7-9-year-old boys who had undergone a programme where traditional games and play had been implement- 
ed demonstrated an increase in motor skill performance. Compared with a control group that performed normal everyday activities, those boys improved their levels of all fundamental motor abilities [15]. It seems that in the case of the above-mentioned study it was possible to predict that additional physical activity (not only traditional games but any kind of physical activity) would bring about positive motor changes. However, Bronikowska [16] pointed to another very important practical aspect concerning the benefits of traditional play and games. They do not require technical perfection. They are mostly quite simple, so they may become a valuable component of movement therapy for the elderly. Because of all those advantages, traditional games and play ought to constitute a crucial tool in the work of PE teachers. They should also be taken into account in educational programmes in physical education students in separate modules, and they should be present to a larger degree in classes in PE methodology as well as practical classes known as "games and play". It is a promising sign that some universities of physical education in Poland offer the subject called "ethnology of sport" in their study curricula.

\section{Conclusions}

1. The teachers examined are insufficiently prepared to introduce traditional games, play, and sports into the process of physical education. This conclusion mainly concerns teachers with the shortest and longest working experience.

2. It is necessary to broaden the programme and educational offerings in the field of national heritage regarding traditional forms of physical activity that come from national cultures.

3. Some of the games and play activities recognised by study participants came from ethnic groups coexisting with Polish culture in eastern Poland. The blending of those cultures, noticeable in traditional games, play, and sports, should be the subject of further research.

\section{Acknowledgements}

The work has been prepared under the research project the Faculty of Physical Education and Sport in Biała Podlaska, Józef Piłsudski University of Physical Education in Warsaw - DS. 201 - financed by the Ministry of Science and Higher Education.

\section{Literature}

1. Renson R. (2009). The come-back of traditional sports and games. Museum International 43(2), 77-81. DOI: 0.1111/ j.1468-0033.1991.tb00947.x.
2. Lipoński W. (2004). Rochwist and Palant. Ethnological study of traditional Polish movement games and play against a background of European tradition. Poznań: AWF. [in Polish]

3. Bronikowska M. (2013). Slavic traditions of folk forms of physical culture as exemplified by selected nations. Poznań: AWF. [in Polish]

4. Cieśliński I., Chaliburda I., Piech K., Cieśliński R. (2007). Ethnology of sport and recreation as an element of education and an area of empirical research. Pedagogics, Psychology, Medical-Biological Problems of Physical Training and Sports 7, 168-172. [in Polish]

5. Prabudzki B. (2013). The study on traditional sports and games as a prospective research area. Homo Ludens 1(5), 205217. [in Polish]

6. Nenadic O., Greenacre M. (2007). Correspondence Analysis in R, with two- and three-dimensional graphics: The ca package. Journal of Statistical Software 20(3), 1-13.

7. Meyer D., Zeileis A., Hornik K. (2015). vcd: Visualizing. Categorical Data. R package version 1.4-1.

8. Cheska A.T. (1978). The study of play from five anthropological perspectives. In M.A. Salter (ed.), Play: anthropological perspectives (pp. 17-35). New York: Leisure Press.

9. Moreno H., Navarro Adelantado J., Jiménez V., Castro Núñez U. (2007). Diachronic analysis of motor communication in traditional games and sports of the Canary Islands. International Journal of Medicine and Science of Physical Activity and Sport 15(57), 123-137.

10. Sutton-Smith B. (1981). The social psychology and anthropology of play and games. In G.R.F. Luschen, G.H. Sage, L. Sfeir (eds), Handbook of social science of sport (pp. 452478). Champaign, Illinos: Stipes Publishing Company.

11. Renson R., van Mele V. (1992). Traditional games in South America. Schorndorf: Karl Hofmann.

12. Piasecki E. (1916). Movement games and play for children and youth from mainly native historical and folk sources and from oral tradition. Lwów-Warszawa: Książnica Polska. [in Polish]

13. Abrignani B. (2011). Traditional sports and games as a tool for intercultural learning. EuroMed Youth Educational Report. Paris: Institut National de la Jeunesse et de l'Éducation Populaire.

14. Czykwin E. (2000). Belarusian minority as a stigmatised group. Białystok: Trans Humana. [in Polish]

15. Akbari H., Abdoli B., Shafizadeh M., Khalaji H., Hajihosseini S., Ziaee V. (2009). The effect of traditional games in fundamental motor skill development in 7-9 year-old boys. Iranian Journal of Pediatrics 19(2), 123-129.

16. Bronikowka M., Bronikowski M. (2011). "You think you are too old to play" Playing games and ageing. Human Movement 12(1), 24-30.

Submitted: January 25, 2016

Accepted: February 29, 2016 